\title{
Energy consumption reduction at all stages of residential buildings life cycle by means of queuing systems
}

\author{
Valeriy Mishchenko ${ }^{1, *}$, Sergei Kolodyazhniy ${ }^{1}$, and Elena Gorbaneva ${ }^{1}$ \\ ${ }^{1}$ Voronezh State Technical University, 20-let Oktyabrya str., 84, 394006, Voronezh, Russia
}

\begin{abstract}
Buildings are the largest source of carbon emissions and energy consumption around the world. Currently, the construction sector focuses on energy efficient and carbon emission reduction technologies to reduce the effect of a green house and improve the environment. The energy aspects of buildings depend on the early design process. The energy consumed by the building can be reduced to $80 \%$ by optimizing the orientation, the shape of the building, the insulation and ventilation during the design and management of the facilities after the completion of the construction. The reductions of energy consumption are fundamental to the International Energy Agency (IEA) goal, which is to reduce global carbon emissions by $77 \%$ against the projected data for 2050 to achieve the stabilized $\mathrm{CO}_{2}$ level provided by the Intergovernmental Panel on Climate Change (IPCC). In this issue, research and development of energy-efficient technologies are important, which play a crucial role in reducing initial costs and increasing energy conservation. To do this, it is recommended to use simulation modeling of the queue management system, which has practical application for both large systems and for private systems.
\end{abstract}

\section{Introduction}

Over the past 50-60 years, energy consumption in the world has skyrocketed due to the increase in population and economic development of countries. The development of the world economy is also accompanied by a rapid increase in energy consumption, by limited types of all fuel (primarily oil and natural gas).

The main trend in the development of world energy is the change in the regional proportions of energy consumption (Table 1), and the main task is to anticipate the trend of outstripping growth in energy consumption due to a decrease in the energy intensity of the economy.

The most urgent task is for countries that are developing with more energy-intensive technologies than developed countries.

\footnotetext{
*Corresponding author: mishenko@vgasu.vrn.ru
} 
Table 1. The structure of energy consumption by regions of the world in years 2000-2016, million tons. e. (Source: BP Statistical Review of World Energy).

\begin{tabular}{|l|c|c|c|c|c|}
\hline & 2000 & 2005 & 2010 & 2015 & 2016 \\
\hline EU-28 & 1731,9 & 1819,3 & 1754,5 & 1626,7 & 1642,0 \\
\hline PRC & 1024,8 & 1823,7 & 2518,6 & 3033,8 & 3081,6 \\
\hline USA & 2309,9 & 2348,7 & 2284,1 & 2275,9 & 2272,7 \\
\hline Middle East & 423,4 & 564,7 & 734,2 & 874,6 & 895,1 \\
\hline $\begin{array}{l}\text { Asia-Pacific } \\
\text { (excluding China) }\end{array}$ & 1623,3 & 1881,9 & 2156,1 & 2413,6 & 2498,1 \\
\hline Russia & 620,3 & 647,2 & 673,3 & 681,7 & 673,9 \\
\hline Africa & 273,6 & 327,4 & 388,9 & 433,5 & 440,1 \\
\hline Other countries & 1383,3 & 1526,1 & 1660,3 & 1765,2 & 1772,8 \\
\hline The whole world & 9390,5 & 10939,0 & 12170,0 & 13105,0 & 13276,3 \\
\hline
\end{tabular}

Having considered the structure of energy consumption by regions in the world, it can be noted that energy consumption growth is uneven. Due to this growth regional energy imbalances are aggravated: the fastest rates are observed in the developing countries of the Asia-Pacific region and in China, where the share of energy consumption in 2016 totaled $42 \%$. Today, there is growth in the number of countries and large regions, the development of which is not provided by its own energy resources.

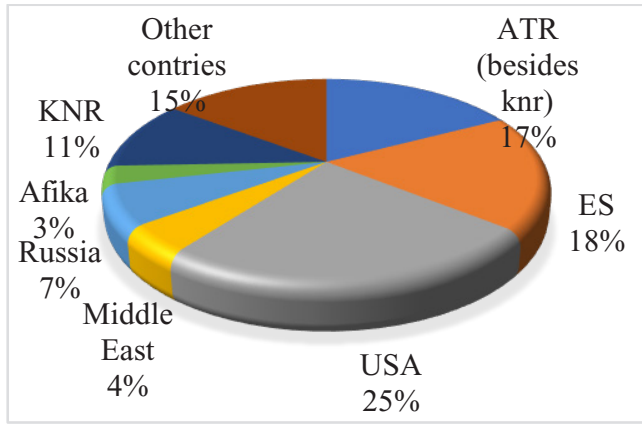

Fig. 1 The structure of energy consumption by regions of the world in the year 2000 .

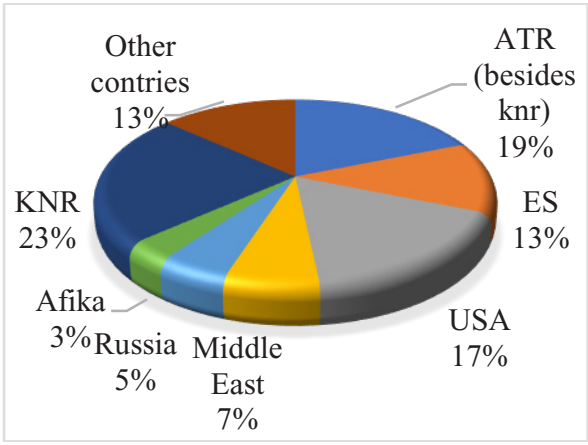

Fig. 2 The structure of energy consumption by regions of the world in the year 2016 .

As can be seen from Fig. 1-2, in 2016 the PRC occupied the largest share in the world level of energy consumption ( $23.21 \%$ compared to $17.12 \%$ of US consumption), the share of energy consumption in the countries of the Asia-Pacific region, the Middle East and Africa increased, the share of final energy consumption in other regions has decreased.

Table 2 shows the structure of energy consumption by types of energy carriers. According to which it can be noted that the largest share in energy consumption is occupied by oil and oil products (34\% in 2016).

Considering the energy consumption in the world over the past 15 years, one can note the change in the structure of energy consumption of some sources, so the share of oil and oil products consumption decreased by $5 \%$, and solid fuel increased by $5 \%$, which led to an increase in $\mathrm{CO}_{2}$ emissions into the atmosphere.

Although the share of renewable sources is only $3 \%$ in total world consumption, but the dynamics of their development for the years 2000-2016 increased 6 times. Consumption of other types of energy did not change significantly. 
Table 2. Structure of energy consumption by types of energy carriers in years 2000-2016, mlllion.tons.e. (Source: BP Statistical Review of World Energy).

\begin{tabular}{|l|c|c|c|c|c|}
\hline & 2000 & 2005 & 2010 & 2015 & 2016 \\
\hline $\begin{array}{l}\text { Oil and oil } \\
\text { products }\end{array}$ & 3589,6 & 3936,3 & 4085,4 & 4341,0 & 4418,2 \\
\hline Gas & 2181,7 & 2499,2 & 2874,2 & 3146,7 & 3204,1 \\
\hline Solid fuel & 2384,7 & 3134,3 & 3635,6 & 3784,7 & 3732,0 \\
\hline Electricity & 1185,4 & 1286,9 & 1404,6 & 1465,9 & 1502,4 \\
\hline $\begin{array}{l}\text { Renewable } \\
\text { sources }\end{array}$ & 49,1 & 82,3 & 170,2 & 366,7 & 419,6 \\
\hline Total & 9390,5 & 10939,0 & 12170,0 & 13105,0 & 13276,3 \\
\hline $\begin{array}{l}\text { The whole } \\
\text { world }\end{array}$ & 9390,5 & 10939,0 & 12170,0 & 13105,0 & 13276,3 \\
\hline
\end{tabular}

A measure of energy efficiency is the ratio of actual consumption to the estimated or estimated amount of energy required to meet various needs in the standard operation of a task. According to the EU Directive on the Energy Consumption of Buildings (EPBD), the following types of heat and electricity consumption are taken into account in the calculation of energy efficiency [1]: heating, hot water supply (DHW), cooling, ventilation, lighting, and other types of energy consumption.

In accordance with the EU Directive "On the Energy Consumption of Buildings (EPBD), more than $40 \%$ of energy consumption in Europe is associated with heating and lighting in buildings. In addition, buildings are the largest source of $\mathrm{CO}_{2}$ emissions, and energy consumption has been growing rapidly since 1990 [6]

Thus, buildings can be considered as energy-intensive systems throughout their life cycle, which is a particularly important indicator related to the operation phase of the building, which accounts for $80 \%$ of total energy consumption [7].

Problems in energy efficiency exist throughout the life cycle of the building (Fig. 3). At each stage of the life cycle, decisions and approaches that make a positive contribution to the creation of more energy efficient buildings can be overlooked.

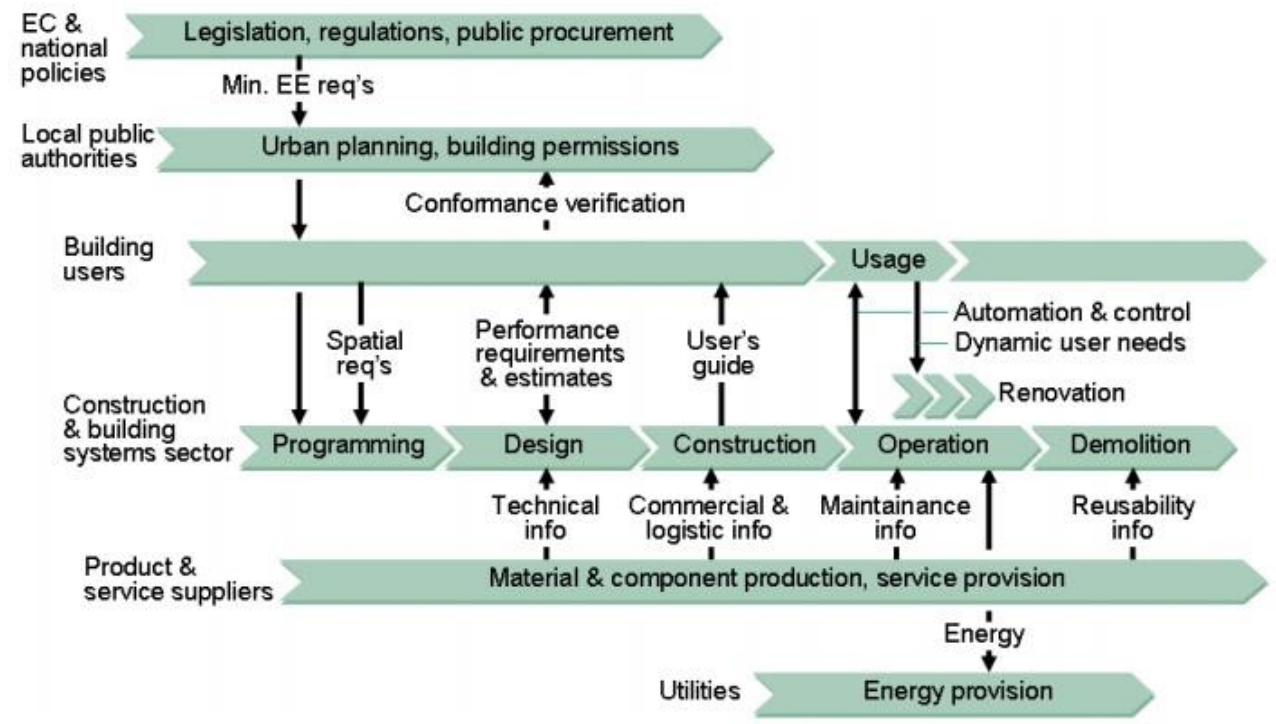

Fig. 3. The concept of energy use in buildings throughout the life cycle. 
Considering the life cycle of a building, three main stages can be distinguished: the design stage (early and detailed design and graphics), the implementation phase and the support phase (maintenance, repair, etc.) [6]:

Design Phase: At the design stage, the emphasis on EE should be to implement the best effective design, taking into account the many variables that can potentially be considered (performance and comfort indicators, construction costs, lifetime costs, etc.). For the designer and engineer, and also in terms of energy efficiency, it is necessary to have a comprehensive and expanded order for optimization (for example, by testing alternative design solutions, material changes, testing various scenarios, etc.) of the overall design to the most suitable design that provides optimal energy.

Implementation phase: in the implementation, the first aspect is the procurement activities and the need to create a process of sustainable procurement, based on typical price and quality criteria to take into account in the case of energy efficiency of purchased materials. Another aspect that is of great importance for the authorities (and therefore for the construction stakeholders) is the assessment of the building's compliance, taking into account existing codes and rules for energy efficiency, creating ratings that would establish separate levels of taxation, taking into account the level of efficiency or adapting building codes and rules for EEs to specific characteristics and properties of location data or applications.

Support phase: from the point of view of the support phase, two types of processes are identified that significantly affect the energy efficiency of buildings - operation and reconstruction. From the point of view of operational activities, there are many possibilities for so-called smart buildings to support more efficient work, namely through observation using network intelligence and control of building devices and systems to maintain a comfortable and operational level while at the same time more energy efficient. Considering reconstruction, an important aspect is how to support the reform of existing buildings in the direction of increasing energy efficiency, thus ensuring a sustainable upgrade and renovation of buildings.

At present, the energy characteristics of buildings are mainly due to regulation. The prevailing market practice is due to the initial investment costs with minimal life cycle costs.

Most of the energy consumed by the building throughout the life cycle is consumed during the support phase. Solutions that affect energy consumption are mainly performed during the design phase, as well as during the repair.

Consider the application of the queue management system (QMS) model for modeling the number of workers in the team for energy-saving measures [15]. Simulation models of queue management systems have great practical application, both for large systems and systems of a private nature $[8-13,16]$.

The quality of the system can be predicted by modeling real processes that can occur during energy saving operations. By changing the parameters of the system, the user can monitor how the performance changes [5] and then decide on what settings the system will run at maximum performance; how many devices should be installed so that the downtime of the device is minimal and the occupancy time is maximum [2]. Of course, absolutely perfect variant of the effective operation of the system cannot be guaranteed, but the results of this simulation will be as close as possible to the real indicators [4].

The construction of a mathematical model for determining the number of workers in the team will be examined using the example of a specific task. Suppose, on average, a year (12 months) of a construction company needs to conduct energy-saving measures in 90 homes. The average duration of such work for 1 house is 2.6 months. In the state of the construction company there are 5 repair brigades, i.e. for each brigade there are an average of 18 houses. It is necessary to determine the optimal number of workers in the team, minimizing the costs of the construction company, like financial, if there are too many workers in the brigade, and 
labor, if the workers are not enough. Therefore, there should be some optimal number of workers in the brigade sufficient to cope with the scope of work.

Since in the system under consideration with an unlimited queue for $\rho<1$ any application that has come into the system will be serviced, then the probability of failure $p_{\text {fail }}=0$, the relative carrying capacity $\mathrm{Q}=1$, and the absolute carrying capacity is equal to the intensity of the incoming order flow $\mathrm{A}=\lambda[16]$.

In order to determine the optimal number of workers in the team, in addition to the efficiency indicators of the queue management system, it is necessary to introduce an optimization criterion. There are several approaches to the choice of such an indicator. It is possible to use a fairly simple and convenient analytical expression of the economic criterion proposed in the works of N. Sh. Kremer.

1. By the condition of the problem, we have: the intensity of the incoming flow of requests for energy-saving measures $\lambda=\frac{18}{12}=1,51 /$ month; service intensity $\mu=\frac{1}{\bar{t}_{\text {об }}}=\frac{1}{2,6}=0,38 \_1 /$ month; average number of busy channels $\rho=\frac{\lambda}{\mu}=\frac{1,5}{0,38}=4,01$

It is known that the queue will not increase to infinity under the condition $\frac{\rho}{n}<1$, that is, when $\mathrm{n}>\rho=4,01$. Consequently, the minimum number of workers in the team should be taken equal to 5 .

2. Let us determine the probabilities of the QMS states at $n=5$.

The probability that the system will not receive requests for the need of energy-saving measures:

$$
\begin{aligned}
& p_{0}=\left(1+\frac{\rho}{1 !}+\frac{\rho^{2}}{2 !}+\frac{\rho^{3}}{3 !}+\frac{p^{4}}{4 !}+\frac{p^{5}}{5 !}+\frac{\rho^{n+1}}{n !(n-\rho)}\right)^{-1}= \\
& =\left(1+\frac{4,01}{1}+\frac{4,01^{2}}{1 \cdot 2}+\frac{4,01^{3}}{1 \cdot 2 \cdot 3}+\frac{4,01^{4}}{1 \cdot 2 \cdot 3 \cdot 4}+\frac{4,01^{5}}{1 \cdot 2 \cdot 3 \cdot 4 \cdot 5} \frac{4,01^{6}}{1 \cdot 2 \cdot 3 \cdot 4 \cdot 5 \cdot(5-4,01)}\right)^{-1}=0,01 .
\end{aligned}
$$

Thus, an average of one percent of the total volume of homes will not perform energy saving.

The probability that in QMS there will be a queue

$$
\mathrm{p}_{\text {que }}=\frac{\rho^{n+1}}{n !(n-\rho)} \mathrm{p}_{0}=\frac{4,01^{6}}{1 \cdot 2 \cdot 3 \cdot 4 \cdot 5(5-4,01)} * 0.01=0,35
$$

3. We calculate the performance indicators of QMS:

average number of requests in the queue

$$
\bar{r}=\frac{\rho^{\mathrm{n}+1} p_{0}}{n \cdot n !\left(1-\frac{\rho}{n}\right)^{2}}=\frac{4,01^{6} \cdot 0,01}{5 \cdot 1 \cdot 2 \cdot 3 \cdot 4 \cdot 5\left(1-\frac{4,01}{5}\right)^{2}}=1,77
$$

average waiting time for queue requests 


$$
\bar{t}_{\text {оч }}=\frac{1}{\lambda} \bar{r}=\frac{1}{1,5} \cdot 1,77=1,18 \text { month }
$$

In order to determine the optimal number of workers, in addition to the efficiency indicators of the queuing system, it is necessary to introduce an optimization criterion. Relative cost is determined by the formula 5 .

$$
C_{\text {rel }}=\frac{1}{\lambda} n+3 \bar{t}_{\text {оч }}=\frac{1}{1,5} \cdot 5+3 \cdot 1,18=6,87
$$

An analysis of the received characteristics of the efficiency of the queue management system indicates the overload of the brigade consisting of 5 workers.

4. To determine the optimal number of workers in the repair team, the performance indicators of the queuing system were calculated with different numbers of workers. The results of the calculations are summarized in Table 3.

Table 3. Indicators of the effectiveness of the queue management system.

\begin{tabular}{|l|c|c|c|c|c|c|c|c|}
\hline Characteristics of the & \multicolumn{7}{|c|}{ Number of workers in the brigade } \\
\cline { 2 - 9 } & 5 & 6 & 7 & 8 & 9 & 10 & 11 & 12 \\
\hline $\begin{array}{l}\text { Probability of team } \\
\text { downtime }\end{array}$ & 0,01 & 0,02 & 0,02 & 0,02 & 0,02 & 0,02 & 0,02 & 0,02 \\
\hline $\begin{array}{l}\text { Number of applications in } \\
\text { the queue for energy- } \\
\text { saving works }\end{array}$ & 1,77 & 0,70 & 0,21 & 0,07 & 0,02 & 0,006 & 0,002 & 0,0005 \\
\hline $\begin{array}{l}\text { Waiting time in queue, } \\
\text { months. }\end{array}$ & 1,18 & 0,47 & 0,14 & 0,04 & 0,014 & 0,004 & 0,001 & 0,0004 \\
\hline $\begin{array}{l}\text { Relative value of costs, } \\
\text { units. }\end{array}$ & 6,87 & 5,41 & 5,08 & 5,45 & 6,042 & 6,67 & 7,34 & 8,21 \\
\hline
\end{tabular}

As follows from the quantitative data given in Table 3, the minimum costs can be obtained with nopt $=7$ people. Additional calculations of other queue management system performance indicators for $\mathrm{n}=7$ have established that pque $=0.09$.

The application of this method of calculating the optimal number of workers in the construction team will save money for the head of the company to pay workers, while fulfilling the annual plan. And when you add different criteria, the model can be improved for each practical situation.

\section{References}

1. Building automation - the impact on energy efficiency. Compliance with EN 15232, http://dom.esco.agency/images/art/1-2016/art63.pdf.

2. Mode of life of the Russian Federation, http://bytrf.ru/remont/sroki-kapitalnogoremonta-mnogokvartirnyh-domov.html

3. A large library, http://www.e-ng.ru/ekonomiko-matematicheskoe_modelirovanie

4. E.P. Gorbaneva, K.S. Sevryukova, The contribution of information and communication technologies to improving the energy efficiency of the construction sector/Information technology in modeling and management: approaches, methods, solutions, 1st AllRussian Scientific Conference (2017)

5. Infopedia for the deepening of knowledge, http://infopedia.su/4x6c97.html 
6. ICT for a Low Carbon Economy. Smart Buildings: Findings by the High-LevelAdvisory Group and the REEBConsortium, http://ec.europa.eu

7. ICT Supported Energy Efficiency in Construction: ISBN 978-951-38-7432-2, http://ec.europa.eu

8. V.Ya. Mishchenko, E.P. Gorbaneva, R. Yun, N.L. Fan, Scientific Herald of the Voronezh State University of Architecture and Civil Engineering, Construction and architecture 3(39), 28-38 (2015)

9. V.Ya. Mishchenko, E.P. Gorbaneva, S.Yu. Archakov, M.G. Dobrosotskikh, FES: Finance. Economy. Strategy. A series of Innovative Economics: the Human Dimension 6, 37-40 (2017)

10. V.Ya. Mishchenko, E.P. Gorbaneva, E.A. Zhdymirova, Scientific Herald of VSUACE, Series: The humanitarian sciences 1, 40-43 (2005)

11. V.Ya. Mishchenko, E.P. Gorbaneva, Interuniversity collection of scientific papers "Actual problems of construction and real estate", Voronezh State University of Architecture and Civil Engineering, 81-86 (2004)

12. V.Ya. Mishchenko, E.P. Gorbaneva, A.Yu. Manukovsky, A.O. Safonov, Scientific Herald of VSUACE, Construction and architecture 3(35), 71-76 (2014)

13. V.Ya. Mishhenko, E.P. Gorbaneva, R. Yoeun, Scientific Herald of the Voronezh State University of Architecture and Civil Egineering 1(29), 27-38 (2016)

14. R. Label, ICT climate change and "green" growth (UN-APCICT, 2011)

15. V.Ya. Khorolsky, Solution of Applied Problems of Electric Power Industry: Textbook (Stavropol State Agrarian University, Stavropol, 2014)

16. Elements of the theory of mass service, http://math.semestr.ru/cmo/cmo_lectures.php 